se encuentran excavados; realizar trabajos en extensión en poblados y ciudades de diferentes tipos y en muchas áreas geográficas; intensificar las prospecciones, desde la conviceión de que deben ser completadas con el estudio de los principales asentamientos; estudiar la función de las casas dentro del asentamiento y de las habitaciones dentro de aquéllas, y la relación que pudo existir entre ciudades y necrópolis. Si somos capaces de llevar a cabo todo ello, el fenómeno urbano y el urbanismo en las culturas ibéricas, que ahora empiezan a entreverse. nos depararán en los próximos años sorpresas tan grandes como aquellas a las que hemos asistido desde el año 1954.

\title{
ESCULTURA IBÉRICA, AYER Y HOY: LA BICHA DE BALAZOTE
}

POR

\author{
MICHAEL BLECH \\ Instituto Arqueológico Alemán, Madrid
}

Las obras de A. García y Bellido ', como la Hispania Graeca (1948) o Las esculturas romanas de la Peninsula Ibérica (1949), y sus diferentes apor-

\footnotetext{
' Se agradece la revisión del texto a M. Tejeiro Díaz y algunas ideas a D. Marzoli y M. Luik Esta aportación presenta la versión resumida de mi charla "Escultura ibérica, ayer y hoy" dada por la amable invitación del Departamento de Arqueologia del CSIC. Mi aportación se concentra en una escultura, la famosa "Bicha de Balazote" tratada magistralmente por el homenajeado Antonio Garcia y Bellido en 1931.

Para la historia de la investigación sobre la escultura ibérica: Chapa Brunet 1980, 20-70; Chapa Brunet 1986; Ruano 1987. 14-53; cf. tambièn Almagro Basch, M.: Las raices del arte ibérico. Papeles del Laboratorio de Arqueologia de Valencia, 11,1975, 251-279. Para la bibliografia de la Bicha de Balazote véase Garcia y Bellido 1931; id. 1954, 578-580; Chapa 1980, 268 27I: id. 1981; id 1985, 234-240; id 1986, $121 \mathrm{n}^{\circ} 219,220-222$; Garcia-Bellido 1992,83-92. Para el toro en las esculturas ibéricas véase Blanco, A .: El toro ibérico, en: Homenaje al prof. C. de Mergelina, Murcia 1961/62, 163-196; cf. además las notas 49-51.

Titulos abreviados: Almagro-Gorbea $=$ Almagro-Gorbea, $\mathrm{M}$. Pozo Moro, MadrMitt, 24, 1983, 177-293. Blech y Ruano 1992 = Blech, M. y Ruano Ruiz, E.: Zwei iberische Skulpturen aus Ubeda la Vieja (Jaén). MadrMitt 33, 1992, 70-111. Chapa Brunet $1980=$ Chapa Brunet, T.: La escultura zoomorfa ibérica en piedra, Madrid 1980. Chapa Brunet $1981=$ Chapa Brunet, T.: E toro androcéfalo de Balazote, Al-Basit 7, $\mathrm{n}^{\circ}$. 10, 1981, 145-157. Chapa Brunet $1985=$ Chapa Brunet, T.: La escultura ibérica zoomorfa, Madrid 1985. Chapa Brunet 1986a $=$ Chapa Brunet, T.: Escultura ibérica: Una revisión de sus interpretaciones, TrabPreHist, 43, 1986, 43-60. Chapa Brunet 1986b $=$ Chapa Brunet, T.: Influjos griegos en la escultura zoomorfa ibérica, Iberia Graeca, Ser. Arqueológica, 11, Madrid 1986. Chapa Brunet $1993=$ Chapa Brunet, T.: La destrucción de la escultura funeraria ibérica, TrabPrehist, 50, 1993, 183-185. Garcia y Bellido 1931a = Garcia y Bellido, A.: Las relaciones entre el arte etrusco e ibero, ArchEspArteA, 7, 1931, 119-148. García y Bellido $1931 \mathrm{~b}=$ García y
}

taciones al mundo ibérico ${ }^{2}$, abrieron vastos campos de conocimiento. Puntos de partida fueron sus cuidadosas descripciones de los objetos, la transfor-

Bellido, A.: La bicha de Balazote. ArchEspArteA, 7, 1931, 249270. García y Bellido $1943 \mathrm{a}=$ Garcia y Bellido, A.: La dama de Elche, Madrid, 1943. Garcia y Bellido 1943b = Garcia y Bellido, A.: Algunos problemas de arte y cronologia ibérica, ArchEspA. 16, 1943, 78-108. Garcia y Bellido $1943 \mathrm{c}=$ Garcia y Bellido, A: De escultura ibérica, algunos problemas de arte y cronologia, ArchEspA, 16, 1943, 272-299. Garcia y Bellido 1954=Garcia y Bellido, A.: Arte ibérico, en: Historia de España, Madrid 1954. vol. I 3, 371-675. Garcia y Bellido $1980=$ García y Bellido, Arte ibérico en España. Madrid 1980. Garcia-Bellido $1990=$ García-Bellido, M. P.: El tesoro de Mogente y su entorno monetal, Valencia 1990. Isler $1970=$ Isler, H. P.: Acheloos, Bern 1970. Isler 1981 = Isler, H. P.: Acheloos, en: L.IMC, Basel 1981, vol. I. 12-36. Jannot 1974 = Jannot, J. R.: Achéloos, le taureau androcéphale et les masques cornus dans l'Etrurie archaïque, Latomus, 33, 1974, 265-289. Llobregat $1966=$ Llobregat, E.A.: La escultura en piedra del Pais Valenciano. ArchArteValenciano, 37. 1966, 41-57. (Llobregat, E. A.: Ilucant 1991, 81-100). Llobregat 1972 = Llobregat, E. A.: Contestania ibérica, Alicante 1972. Llobregat $1991=$ Llobregat, E. A.: Ilucant, Alicante 1991. Olmos $1986=$ Olmos, R.: Anotaciones preliminares al libro de Teresa Chapa, en : Chapa 1986, 7-38. Olmos $1992 \mathrm{a}=$ Olmos, R.: El surgimiento de la imagen en la sociedad ibérica, en: Sociedad 1992, 8-32. Olmos $1992 \mathrm{~b}=$ Olmos, R.: Religiosidad y vida cotidiana en la España ibérica, Seminarios Fons Mellaria, 1991, 11-45. Paris 1903 = Paris, P.: Essai sur l'art et l'industrie de 1'Espagne primitive (1903). Ruano Ruiz 1987 = Ruano Ruiz, E.: La escultura humana de piedra en el mundo ibérico, vol 1-III (1987). Sociedad $1992 / 93=$ La sociedad ibérica a través de la imagen, Cat. Albacete etc.,1992/93. Tarradell $1965=$ Tarradell, M.: Arte ibérico, Barcelona 1968. Trillmich $1975=$ Trillmich, W.: Ein Kopffragment aus Verdolay bei Murcia, MadrMitt 16, $1975,208-245$.

${ }^{2}$ Garcia y Bellido 193 la.b. 1943a.b. 1954. 1980. 
mación de inventarios en catálogos y la sintesis de la investigación previa, todo ello futura base de sus interpretaciones. Su obra permanece vigente hoy en dia, a pesar de los defectos propios de la época. Precisamente los errores provocaron fructiferas respuestas. Uno de estos temas polémicos es la definición de "lo ibérico".

Su primer trabajo sobre un tema del mundo ibérico y su primera aportación monográfica sobre una escultura ibérica trata de la Bicha de Balazote ${ }^{3}$. Esta aportación ya supone la existencia de la cultura ibérica como un concepto evidente que abarca no sólo la lengua y la etnografia ${ }^{4}$ dentro de un marco temporal y sus relaciones con el mundo mediterráneo y oriental. Asi, P. Bosch Gimpera s y Rh. Carpenter ${ }^{6}$ buscaron los modelos de la Bicha de Balazote en el mundo griego, mientras que L. Heuzey ${ }^{7}$ y P. Paris ${ }^{x}$ los buscaron en el mundo oriental antiguo.

García y Bellido matiza este planteamiento del problema. La revisión iconográfica del toro andrósopo lo llevó a dos posibles orígenes: la Magna Grecia y Sicilia, entre finales del siglo vi hasta el siglo IV a.C., y especialmente a Etruria ${ }^{9}$, con el toro andrósopo echado, como demuestran algunos relieves arcaicos de cipi sepulcrales de Chiusi ${ }^{10}$, y el aplique de un asa etrusca procedente de un taller de Vulci, encontrada en Málaga " , a donde llegó debido a las importaciones del comercio púnico. Este último testimonio, que Garcia y Bellido no pudo conocer, ofrece no sólo un ejemplo muy próximo, sino también

\footnotetext{
'Garcia y Bellido $1931 \mathrm{~b}$.

+Cf. para la historia de la investigación Chapa Brunet 1980. 19-70 esp. 23-30; id. 1986, 43-60; Ruano 1987, 12-53. Para la palabra cultura uibérica» Dominguez Monedero, A. J.: Los términos "lberia» e "lberos" en las fuentes grecolatinas: estudio acerca de su origen y ámbito de aplicación, Lucentum 2, 1983. 203-224. Para la defínición de lo ibérico como un reflejo histórico $c f$. Ruiz, A. y Molinos, M.: Los Iberos, Barcelona 1992. 14-22.

${ }^{5}$ Bosch-Gimpera, P.: Beziehungen der iberischen zur griechischen Kunst, en 25 Jahre Römissch-Germanische Kommission, Berlin-Leipzig 1929, 86s.

${ }^{\circ}$ Carpenter, Rh.: Ther Greeks in Spain, Londres 1925, 161.

${ }^{7}$ Heuzey, L., Monuments e Mémoires Piot 1901, 122s.; Ol$\operatorname{mos} 1992,14$.

${ }^{8}$ Paris $1903,121$.

${ }^{9} \mathrm{Cf}$. Garcia Bellido 1990, 95: Jenkins, G. K.: The Coinage of Gela, AMUGS 1I, Berlin 1970, 165-175; Isler 1970, 6896 $131 \mathrm{n}^{\circ} .50$; id. $1981,29 \mathrm{n}^{\circ} 278$. Cf. también el ascos del Emporion (Trias de Arribas, G.: Cerámicas griegas de la Península lbérica, Valencia, 1967, $45 \mathrm{n}^{\circ} .44$ lám. 8) de un taller griego de Sicilia.

${ }^{10} \mathrm{C} f$. los remates clusinos con representaciones heráldicos: Jannot, J. R.: Les Reliefs archaïques de Chiusi, Roma 1984, 180 $n^{\circ}, 1-3$.

"Véase Blanco, A.: Ein figürlich verziester bronzener Oinochoenhenkel aus Málaga, MadrMitt, 6, 1965, 84-90; Gran-Aymerich, J.: Malaga phénicienne et punique, Paris 1991, 131s. y
} lám. 3. una idea de un posible modelo para nuestra Bicha Asi, jarras similares a la del asa de Pozo Moro pudieron encontrar su camino hasta el hinterland de la costa levantina ${ }^{12}$, donde existió la voluntad y habilidad de transformar un motivo propio de las artes menores en gran plástica ${ }^{13}$.

De todas formas los ejemplos aducidos permitieron a Garcia y Bellido algunas conclusiones: «... hay suficientes motivos para abandonar la tesis antigua que hacia de la Bicha de Balazote un documento demostrativo de la existencia de remotas relaciones entre nuestra Peninsula y el Oriente Mesopotámico. La cronologia que de esta tesis se deriva queda, por consiguiente, también rectificada por la clara cronologia que los prototipos griegos o pseudogriegos de todo el Mediterráneo llevan. Nuestra "Bicha de Balazote"... es hija de helenos, pero hermana de nuestras esfinges ibéricas, de los bronces de la Luz, de las cabezas del Cerro de los Santos y de la misma Dama de Elche» ${ }^{14}$. El motivo de nuestra Bicha de Balazote, el del toro echado, queda como un caso excepcional aunque algunas monedas aisladas de Emporión, del siglo IV a.C., y de Sagunto ${ }^{15}$ documentan el toro caminando, motivo que tiene sus paralelos más próximos en las regiones de la Magna Grecia y Sicilia ${ }^{16}$. García y Bellido busca las comparaciones estilisticas ibéricas en el gran conjunto de los exvotos del Cerro de los Santos. Precisamente las cabezas de estas esculturas ofrecen «paralelos técnicos», apreciables sobre todo en la presentación geométrica y decorativa del peinado y de la barba de la Bicha de Balazote ${ }^{17}$. Esta observación nos acerca un poco más a lo propio, «a lo ibérico».

Este problema está planteado en dos trabajos posteriores de Garcia y Bellido ${ }^{18}$. La labra de las piedras - las superficies continuas, miembros angulosos, el tallado en bisel, los trazos geométricos etc.- denuncian la mano de «un escultor que ave-

\footnotetext{
${ }^{12}$ Almagro-Gorbea 1983, 184 y lám. 15b. En general véase Garcia y Bellido 1931; Llobregat 1982. Para los hallazgos etruscos véase Alvar, J.: El tráfico comercial etrusco hacia el Extremo Occidente, en : Navies and Commerce of the Greeks, the Cartaginians and the Etruscans in the Tyrrehenian Sea, Symposium Ravello 1987, 1988, 373-389: Cf. Dominguez Monedero, A. J.: El enfrentamiento etrusco-foceo en Alalia, en: La presencia de material etrusco en la Península Ibérica, Barcelona 1991. 263-269 esp. 268s.

${ }^{13}$ Para la presencia etrusca véase Blázquez Martinez, J. M. La presencia de artesanos etruscos en Tartesos, en: Presencia.. (cit.) 597-600 1991; Cf. Gran-Aymerich, J.: cit. (n. 11) 128-139. ${ }^{14}$ Garcia y Bellido $1931,262-270$.

${ }^{15}$ Villaronga Garriga, L.: Las monedas de Arse. Saguntum, Barcelona 1967.

${ }^{16}$ Garcia-Bellido $1990,83-92$.

${ }^{17}$ Garcia y Bellido 1931b, 266s

${ }^{18}$ Garcia y Bellido 1943a. b.
} 
zado a la talla lignaria, elige una piedra blanda para labrarla, quizá con los mismos instrumentos carpentiles que acostumbra " $"$ ". El interpreta estas observaciones a la manera de fósil-director, como los "survivals" de una fase anterior, la etapa xoánica de la escultura ibérica en analogia con una supuesta fase de la escultura griega ${ }^{21}$. Este rasgo,que se puede apreciar en toda la escultura ibérica ${ }^{21}$, se mantuvo a lo largo de los siglos por la tendencia conservadora y tradicionalista propia del «provincialismo» de todo el arte ibérico. La Dama de Elche misma ofrece este rasgo. El plegado de sus paños no está en relación con la magnifica talla de su rostro, que denuncia la mano de un escultor que conoce lo «clásico-helenístico", mientras que los pliegues traducen fórmulas datables quizá dos siglos antes. Este plegado geométrico en lineas paralelas o en zigzag es evidentemente un "pseudoarcaicismo", supervivencia estereotipada de una técnica en madera ${ }^{2 ?}$.

Este planteamiento tiene sus consecuencias: los rasgos «pseudoarcaicos» son una constante en esta escultura y no se pueden tomar como indicios cronológicos, porque entonces el estilo de la escultura ibérica se revelaria como un fenómeno conservador y por lo tanto sin valor cronológico. Así, los influjos foráneos tendrían casi inevitablemente una importancia decisiva, ya que no sólo marcarían las pautas en cuanto a la cronología, sino también en cuanto a su significado.

El caso de la Bicha de Balazote nos puede servir como ilustración. Por un lado pertenece al primer grupo, a los evidentes trasuntos, más o menos directos, de modelos griegos arcaicos, fechables entre mediados del siglo vi y mediados del siglo v, aunque su fecha más probable, según García y Bellido, deba calcularse hacia el siglo III ó más recien$\mathrm{te}^{23}$. Así, aspectos como el alejamiento de los modelos griegos - compárese en nuestro caso especialmente el cuello alto voluminoso y los rasgos faciales geometrizados - y la calidad ofrecen una escala para la clasificación cronológica. Cuanto más se valoró la parte ibérica, tanto más se distanció de

\footnotetext{
${ }^{14}$ Garcia y Bellido 1943b, 79.

${ }^{20}$ Garcia y Bellido 1943b, 78-82: «De los griegos sabemos que una de las fases artísticas más primitivas, y precisamente la que proporcionó luego la entrada de la estatuaria monumental, la conformaron los escultores en maderan; pera este tema. $C f$. Herrmann, H. V.: Zum Problem der Entstehung der griechischen Grosssplastiik, en: Wandlungen, Homenaje E. Homann-Wedeking, Waldsassen $1975,35-52$ esp. 37 .

${ }^{21}$ Véase abajo Herrman, H. V. cit. (n. 20) 17

${ }^{22}$ Garcia y Bellido 1943, 82-84: Cf. Nicolini, G.: Les bronzes figurés des sanctuaires ibériques, Paris 1969, 256 s.

${ }^{23}$ Garcia y Bellido 1943c, 277.
}

las influencias helénicas, llegando finalmente hasta la época de la romanización ${ }^{24}$.

Esta postura dio lugar a una serie de respuestas contrarias. Precisamente las relaciones más opuestas son las de E. A. Llobregat y M. Tarradell ${ }^{25}$, reflejando en el fondo ambos un mejor entendimiento del planteamiento de este problema que los cientificos que to dejaron pasar por alto. Estos comprendieron bien que un entendimiento acertado de to "ibérico» tiene también sus consecuencias a la hora de establecer una cronologia más correcta, mientras que otros buscaron la relación directa con un prototipo, pensando en artistas griegos, artistas iberos de formación griega, etc. ${ }^{26}$.

E. A. Llobregat expresa su opinión de manera positiva: «La evidencia arqueológica nos obliga a postular una indigenidad, una autoctoneidad para el arte ibérico, y una vez aceptado este postulado, hay que llevarlo a sus últimos extremos y comparar la escultura ibérica con la escultura ibérica...» que vista en bloque constituyera un todo, «basada en una voluntad de estilo manifiesta". "Que en esta "voluntad de estilo" ${ }^{27}$ haya una elaboración vieja de la que corrientes griegas arcaicas, etruscas, fenicias o púnicas formen parte, no empaña en absoluto la radical unidad del conjunto, ni justifica que se llame arte provincial o arte hecho por griegos en el suelo del país.» Lógicamente las huellas que dejaron las llamadas corrientes griegas arcaicas, etc., apenas influian en la datación de las esculturas ibéricas, siendo las dataciones de los propios contextos ibéricos lo realmente decisivo, como sucede por primera vez con las excavaciones de La Alcudia de Elche, por A. Ramos Folqués ${ }^{28}$.

\footnotetext{
${ }^{24}$ Llobregat 1991, 95-100.

${ }^{25}$ Tarradell 1968, 132. 150 destaca la personalidad de esta escultura sin excluir inspiraciones y contactos, «No resulta demasiado aventurado suponer que en su origen algún escultor griego pudo tener participación directa en la creación de la escuela y del estilo.

${ }^{20}$ Cf. p.e. Blanco.: La Antigüedad 2, Historia del Arte Hispánico vol.1. Madrid 1981, 41: Blázquez, J.M. y Gónzález Navarrete, J. : The Phokain Sculpture of Obulco in SouthernSpain, AJA 89, 1985, 61-69 esp. 68. Según ellos las colonias griegas en la costa levantina jugaron un papel más importante que lo que en realidad teniản.

${ }^{27}$ Llobregat 1972, 164. Esta palabra recuerda a la del «Kunstwollen" acuñada por Riegel, A.: Spätrömische Kunstindustrie (2nda ed., Viena 1927).Hemos utilizado la traducción española: " El arte industrial tardorromano», La balsa de Medusa 52 (Madrid 1992), 299-310. Esta teoria se refiere al gusto especifico de una época expresado en determinadas manifestaciones artísticas (Bianchi Bandinelli, R.: Introducción a la arqueologia «Barcelona 1992 " 144), en este contexto, tiene un cierto resabio de G. Kossinna: Cf. Smolla, G.: Das Kossinna-Syndrom, FbHessen 19/20, 1979/80, 1-9.

${ }^{28}$ Ramos Folqués, A.: La Dama de Elche, datos para su cronologia, en: Crónica del III Congr. Arq. del Sudeste Español,
} 
Una revalorización de lo ibérico se anuncia también en el bosquejo de M. Tarradell sobre "El arte Ibérico" (1968) ${ }^{20}$. Este tiene en cuenta por un lado las inspiraciones foráneas - en el fondo también Llobregat contó con ellas-y un proceso de asimilación, y por otro lado la autonomia de la escultura ibérica. Además habla de la dimensión sociológica, de la relación entre el artesano y su clientela, opinión que se refleja más tarde en los trabajos como los de T. Chapa o A. Ruiz Rodríguez y otros.

Un detalle de este proceso tan complicado de la "asimilación» está desarrollado en una aportación de W. Trillmich ${ }^{30}$ basándose en la cabeza fragmentaria de Verdolay en Murcia. Se refiere a las diferencias, o más concretamente, a las distancias entre un modelo, es decir la inspiración concreta, y la obra ibérica. De manera ejemplar describe de un lado los rasgos recibidos del estilo severo griego y por el otro la parte indigena, la reinterpretación: el proceso con-sisitiría en una estricta abstracción y estilización de los rasgos aislados y una expresión hierática en su conjunto. Sólo en este sentido se podria hablar de estilo de esta cabeza. En cuanto a la conformación arcaica del ojo, más que un anacronismo, se trataria precisamente de una caracteristica ibérica propia-mente dicha: A este respecto, sería indiferente que la conformación del ojo se base en modelos arcaicos. Lo mismo sucede con la estilización del peinado ${ }^{31}$. Su argumentación concluye con un resultado metodológico. La reinterpretación de una escultura de la Magna Grecia, de mediados del siglo v a.C. y con la misma forma de la cabeza que la de Verdolay, permitiria hacer dos propuestas cronológicas: que la cabeza haya sido creada poco después que el modelo, o que sea un reflejo tardio de éste. El material disponible, en su mayoría sin contexto, no era suficiente para poder tomar una decisión ${ }^{32}$.

La descripción en detalle del distanciamiento de los esquemas interpretativos ibéricos con respecto a los prototipos griegos no nos permitiria una paralelización demasiado rápida. Por esta razón la falta de calidad de una pieza no se puede calibrar según su distanciamiento de los posibles modelos griegos, sino en comparación con otras obras ibéricas. Y el preguntarse por la presencia de artesanos griegos dentro del mundo indígena pierde importancia. Tal vez algunos de sus emigrantes proporcionaron el

\footnotetext{
Murcia 1947, 153-158 esp. 155-157; Ramos Fernández, R.: La ciudad romana de Illici, Alicante 1975, 105-121.

${ }^{29}$ Tarradell 1968, , 160, 169. Cf. 132. 134

${ }^{30}$ Trillmich 1975; Ruano 1987, vol.III $55 \mathrm{Mu}-3$.

${ }^{31}$ Trimllich 1975, 214-216.

${ }^{32}$ Trimllich 1975,244 s.
}

primer impulso a artesanos y clientes indigenas is En cualquier caso, los iberos estuvieron en situación de seleccionar e interpretar los modelos y motivos foráneos según sus tradiciones ${ }^{34}$.

Las tendencias abstractas se expresaron de manera diversa $y$, a veces, incluso desconcertante: por ejemplo los dos jinetes de la necrópolis albaceteña de Los Villares ${ }^{\text {it }}$, el guerrero a caballo de principios del siglo v a.C.. con sus rasgos faciales regulares similares a los de algunas cabezas raciales de la necrópolis del Llano de la Consolación ${ }^{\text {th }}$ y a las de Cerrillo Blanco ${ }^{37}$, aunque más lejanas, frente al hombre a caballo a finales de ese mismo siglo, caracterizado por una estilización sistemática; o entre algunas «barrocas» esculturas ilicitanas frente a la austeridad de las de Cerrillo Blanco de Porcuna ${ }^{3 x}$; o entre las dos cabezas de esfinges de "Alicante» y la de Ubeda la Vieja, que reflejan las mismas tendencias hacia formas geométricas y estilizadas ${ }^{39}$, etc. ${ }^{40}$.

Después de dar tantas vueltas volvemos a nuestra escultura de la Bicha de Balazote, que carece de contexto y constituye una tipología casi aislada dentro de la plástica ibérica, a excepción del toro echado, sin cabeza, de Agost $^{41}$; además no ofrece ningún indicio preciso que sirva para su clasificación cronológica. Sólo su conformación - las superficies lisas y tensas y en especial los rasgos faciales reducidos a líneas esbozadas sobre la forma abstracta de la cabeza, un volumen compacto y cilindrico - nos hace pensar en las características de algunas estructuras fechables, como las de La Alcudia de Elche o las del Cerrillo Blanco de Porcuna, del siglo $\mathrm{v}$ a.C. También se puede comparar con las esfinges de Agost ${ }^{42}$ y de Haches ${ }^{43}$, cuyos rostros, a la manera de máscaras, parecen estar sobrepuestos sobre la cara, y el cuello en forma de columna y además la actitud atenta y erguida, su cara vuelta hacia el espectador, como un motivo que formó parte del repertorio de los escultores ibéricos inspirado por modelos griegos.

\footnotetext{
"Blech y Ruano 1992, 83-92.

${ }^{14} \mathrm{Cf}$. Olmos 1986,10-14.

${ }^{15}$ Blánquez Pérez, J.: Primeras aportaciones arqueológicas sobre la cronologia de la escultura ibérica, en : Homenaje a J.M. Blázquez, vol. II, Madrid 1994, 125-138.

${ }^{36}$ Blech y Ruano 1992, 76 y lám. 6b.

"Nogueruela Martinez, 1.: Los monumentos escultóricos ibéricos del Cerrillo Blanco de Porcuna, Madrid 1990.

${ }^{3 x} \mathrm{P}$. e. Blech, M.: Varianten der südwesteuropäischen Beinschienen in der iberischen Plastik, MadrMitt 29, 1988, 188-190

${ }^{34}$ Blech y Ruano 1992. lám. 1. 3.

${ }^{40} \mathrm{Cf}$. Olmos 1986, 19s. Estas tendencias abstractas se repiten tambièn en otras culturas, el caso griego, es decir el desarrollo de la figura hacia un cierto "realismo", es un caso especial: $c f$. Gombrich, E. H.: Kunst und Illusion, Stuttgart 1978. 143.

4' Paris 1903, 122 y fig. 93; Chapa 1980, 140-142.

${ }^{42}$ Chapa 1986 b, 115 n ${ }^{\circ} .194 .251$ y fig. 3

${ }^{43}$ Chapa 1986,116 s. no. 197
} 
Otro argumento nos lo ofrece el «horizonte de la destrucción escultórica" " que pone fin a una época iconográfica ibérica muy rica, en la que también podria encajar nuestra Bicha de Balazote y la serie de las esfinges, los centauros, etc. Asi obtenemos una cierta cronología entre la época de los posibles prototipos, es decir los años alrededor 500 a.C., y el "horizonte de las destrucciones» (véase nota 44), es decir, entre principios y finales del siglo $\mathrm{v}$. Sólo entonces, habiendo obtenido la clasificación cronológica de una pieza, «lo ibérico» asume su importancia histórica.

El conjunto arquitectónico al que pudo pertenecer nuestra figura no está muy claro. El monstruo aparece echado sobre una especie de plinto, si se mira de frente. Verosímilmente formó parte de una esquina de un monumento arquitectónico, una posible tumba, porque la zona delantera del cuello y de la pata derecha están esculpidas casi por completo, mientras que la parte trasera está formada por una superficie tosca, de contorno irregular y bordes curvados que no pudo coincidir con la de una hilada de sillares en el muro ${ }^{45}$. «Por lo dicho - según Garcia y Bellido-, es probable que estuviese más o menos arrimada en una pared $)^{46}$. Pero si se tratara de daños recientes que hubieran afectado al contorno de la parte trasera, podriamos pensar en una función similar a la de los leones del monumento sepulcral de Pozo $\mathrm{Moro}^{47}$. De todas formas la Bicha de Balazote perteneció a un conjunto arquitectónico y muy probablemente a un monumento sepulcral, teniendo la misma finalidad de guardián de las esfinges, los leones o los toros ${ }^{48}$.

La postura echada del monstruo sobre una tum-

\footnotetext{
${ }^{44}$ Chapa 1993, 185-195 (con la bibliografia).

${ }^{45}$ Pero véase Almagro-Gorbea 1983, $232 \mathrm{n}^{\circ}$. 7 .

${ }^{46}$ Garcia y Bellido 1931b, 264.

"Almagro-Gorbea 1983, 193s y lám 16-22. Una cierta alternativa nos ofrece Sanmarti Grego, E.: Notas acerca de un bóvido ibérico en piedra del Mus. Arq. de Barcelona, AnPrehistLev, 17, 1987, 261-273 esp. 272 reconstruye la Bicha de Balazote en relación con una dama sedente.

${ }^{4 x}$ Olmos 1992b, 29.
}

ba dentro de un conjunto arquitectónico podria subrayar este carácter de guardián ${ }^{44}$. en contraposición con la de un animal caminando, que reflejaría un movimiento, caso del toro andrósopo Aqueloo, que en el mundo griego representaba los ríos y las fuentes. ¿Tenemos por esto que suponer un cambio del significado de nuestro motivo? A pesar de estas observaciones quedan algunas objeciones contra esta interpretación tan formal de un caso aislado: cabria la posibilidad de que nuestro toro hibrido fuera uno de esos toros monumentales que E. A. Llobregat relacionó con la idea de las aguas ${ }^{50}$.

Las posibles ideas asociativas que los iberos pudieran tener en torno a esos temas no nos es posible materializarlas más, si queremos evitar conclusiones fáciles y simplistas ${ }^{51}$. En todo caso el monumento mismo sirvió para destacar al personaje sepultado y a su gens del resto de su sociedad y con tema tan especial el individuo reflejó su gusto exótico $^{52}$. El contexto perdido - su situación dentro del conjunto de una necrópolis ${ }^{53} \mathrm{y}$ su marco topográfi$\mathrm{co}^{54}$ - hubieran podido decirnos algo sobre este personaje aristocrático y su mundo. Precisamente estos aspectos iconográficos, religiosos y sociológicos de lo «ibérico» deberán ser matizados en el futuro; y fundamentos para ello existen.

\footnotetext{
49 Jannot, 1974, 774.

50 Llobregat, E. A.: Toros y agua en los cultos funerarios ibéricos, Llobregat, E. A.: Ilucant 1991, 209-216 esp. 214s. (Saguntum 16, 1981, 149-164); cf. Olmos 1992, 23.

"' Para materiales de una interpretación del motivo del toro véase p. e. Maier, F.: Eine Germanische Stierfigur der Späten Kaiserzeit ausx dem Rhein-MainGebiet, Germania, 59. 1981, 331. 356: Luik.M., y Scharch-Dörges, H.: Römische und frühalemanische Funde von Beistein, FbBaden-Württemberg 18, 1993, 356361.

${ }_{52} \mathrm{Cf}$. Olmos 1986, $2 \mathrm{Is}$

"Véase Almagro-Gorbea, M.: El "paisaje» de las necrópolis ibéricas y su interpretación sociocultural,RStLig, 44, 1978, 199 . 218.

${ }^{54}$ Chapa Brunet 1981, 151s.; Chapa Brunet, T.: Panorama general de la escultura ibérica en el Alto Guadalquivir, en: Homenaje a J. M. Blảzquez, Madrid 1994, vol II, 1994, 125-138; cf. también Dominguez Monedero, A. J., en: Chapa Brunet 1986b, $311-330$
} 